\title{
Psychosurgery for schizophrenia: history and perspectives
}

\author{
This article was published in the following Dove Press journal: \\ Neuropsychiatric Disease and Treatment \\ 12 April 2013 \\ Number of times this article has been viewed
}

\author{
Matheus Schmidt Soares \\ Wellingson Silva Paiva \\ Eda Z Guertzenstein \\ Robson Luis Amorim \\ Luca Silveira Bernardo \\ Jose Francisco Pereira \\ Erich Talamoni Fonoff \\ Manoel Jacobsen Teixeira \\ Division of Neurosurgery, Hospital \\ das Clínicas, University of Sao Paulo \\ Medical School, Sao Paulo, Brazil
}

\begin{abstract}
Following the early studies of Moniz and Lima, psychosurgery had considerable scientific credibility until the advent of modern antipsychotics in the mid 1950s. Thereafter, psychosurgery was almost abandoned in large medical centers as a common treatment for schizophrenia, although is still used for some affective and anxiety disorders. We reviewed relevant papers cited in the Medline/Index Medicus, Cochrane, and Scielo databases from 1930 to 2012. In our review of the literature, we show from recent studies that there are still many patients with schizophrenia who have serious deficits even after being treated with current noninvasive therapies. The value of psychosurgery remains controversial. There are no data available to support the use of stereotactic procedures for schizophrenia. Well designed controlled trials are needed to establish the effectiveness of psychosurgery in patients with schizophrenia.
\end{abstract}

Keywords: psychosurgery, schizophrenia, treatment, stereotactic techniques

\section{Introduction}

Schizophrenia is a chronic disease with a prevalence of $0.4 \%-1.0 \%$ depending on the study, and is evenly distributed worldwide. ${ }^{1-7}$ Despite the low incidence $(0.16-0.42$ per 1000 individuals), ${ }^{8}$ the prevalence is high because of the chronic nature of the illness. Even after remission of the characteristic signs of schizophrenia, some residual features may be present. These include lack of interest and initiative in daily activities and work, social incompetence, and lack of interest in pleasurable activities. ${ }^{9,10}$ In a study conducted in $2000,{ }^{8}$ it was found that schizophrenia is responsible for $1.1 \%$ of all disability-adjusted life years and $2.8 \%$ of years lived with disability. Data from a US study of schizophrenia showed a direct cost of \$US 19 billion, with an additional cost of \$US 46 billion resulting from decreased productivity. Approximately 10\%-20\% of patients with schizophrenia develop chronic disease and deterioration. ${ }^{11}$

Approximately $27 \%$ of patients with schizophrenia have a history of substance abuse, of whom $11 \%$ report substance dependence in the last year. ${ }^{12}$ Self-aggression or aggressiveness towards others is another aggravating factor. ${ }^{13}$ One study reported that $30 \%$ of patients with schizophrenia have attempted suicide ${ }^{14}$ and another reported that $10 \%$ did kill themselves. ${ }^{15}$ Several studies associate this behavior with comorbidities such as depressive disorder, which has a prevalence of $60 \%,{ }^{14,15}$ including an increased use of legal or illegal drugs. ${ }^{6}$ Accordingly, it is estimated that the life expectancy of patients with schizophrenia is approximately $10 \%$ lower than for individuals without the disease.

One of the possible treatments for this complex disorder includes psychosurgery. There have been numerous reports of psychosurgery in the past, ${ }^{1}$ and initial
Correspondence: Wellingson Silva Paiva Rua Eneas Aguiar $255,5^{\circ}$ Andar, São Paulo, Brazil 054030I0

Tel +55 II 25486900

$\mathrm{Fax}+55$ II 25486906

Email wellingsonpaiva@yahoo.com.br 
psychosurgery for the treatment of schizophrenia based on scientific knowledge dates from 1888, when the Swiss psychiatrist Gottlieb Burckhardt operated on six patients with chronic schizophrenia. ${ }^{2}$ The results were not favorable, and his work was rejected by the scientific community at the time. However, from 1937 onwards, after the development of the frontal lobe disconnection technique, ie, the leucotomy, by the Portuguese neurologist Egas Moniz, assisted by the neurosurgeon Almeida Lima, this type of surgery became widespread during the 1930s and 1940s. However, it was gradually abandoned by larger medical centers after the discovery of more effective antipsychotics, of which chlorpromazine, which has been available since $1954,{ }^{3}$ was foremost.

After the advent of stereotaxy, psychosurgery re-emerged as an option for the most severe, chronic, and refractory cases, primarily when patients with schizophrenia pose a threat to themselves and/or to others. ${ }^{4}$ In this article, we investigate the current role of psychosurgery in the treatment of schizophrenia, bearing in mind the most current and relevant scientific knowledge about the illness and the surgical techniques used to treat it.

\section{Materials and methods}

We conducted our literature search using the Cochrane Controlled Trials Register of the Cochrane Library, Embase, Scielo, and Medline databases. We included studies published between 1930 and 2012 on stereotactic psychosurgery for the treatment of schizophrenia. We used the following MeSH terms and combinations: "schizophrenia", "psychosurgery", and "stereotactic techniques". For all studies identified, the "Related Articles" feature in PubMed was used to locate additional relevant studies. Titles and abstracts of references identified by the search were screened independently by two reviewers (RLA and WSP) for their potential relevance. We excluded case reports, nonstereotactic treatment, schizoaffective disorders, and articles not written in English, French, or Japanese. Our literature search strategy yielded 70 publications, of which eight including a total of 56 patients, fulfilled the predefined inclusion criteria. Most excluded studies were related to nonstereotactic frontal leucotomies $(n=21)$ or were reviews $(n=11)$. No prospective controlled trials were found. All studies were presented as case series. Table 1 summarizes the types of procedure performed and patient outcomes. Because of the use of heterogeneous parameters to assess outcome in these studies, we categorized the patients according to "improvement", "partial improvement", and "no improvement".

\section{Anatomical basis}

Neuropathological and neuroimaging studies have helped to generate the hypothesis of a new diencephalic and/or temporolimbic disease with frontal lobe secondary malfunction, usually arising from a primary disease in that region. ${ }^{16}$

Jenkins et $\mathrm{al}^{17}$ proposed that signs of schizophrenia could be caused by "some kind of morbid resonance" in the diencephalon (thalamus) and the prefrontal cortex. They suggested that this pathological process could be repaired by destruction of the frontal cortex, thalamus, or connection fibers. In 1984, the Psychiatric Therapy Commission of the American Psychiatric Association established that "as a result of the experience of the surgery in different parts of frontal lobes, the developed consensus is that the best results with minimal adverse changes in personality are obtained by sectioning the fibers that pass from and to the ventromedial and orbital portion of the cortex" and that "the limbic system plays an important role at the evocation of emotional phe-

Table I Summary of papers published on stereotactic procedures performed in patients with schizophrenia

\begin{tabular}{|c|c|c|c|c|c|c|}
\hline Authors & Type of study & $\mathbf{n}$ & Stereotactic procedure & Improvement & Partial improvement & No improvement \\
\hline Jiménez-Ponce ${ }^{23}$ & Case series & 2 & $\begin{array}{l}\text { Cingulotomy and anterior } \\
\text { capsulotomy }\end{array}$ & 2 & 0 & 0 \\
\hline da Costa 24 & Case series & 16 & $\begin{array}{l}\text { Bilateral leucotomy } \\
\text { (hypothalamotomy plus } \\
\text { cingulotomy or fundus stria } \\
\text { terminalis plus cingulotomy) }\end{array}$ & 14 & 2 & 0 \\
\hline Ballantine et $\mathrm{al}^{33}$ & Case series & 11 & Cingulotomy & 4 & 4 & 3 \\
\hline Mitchell-Heggs et $\mathrm{al}^{22}$ & Case series & 7 & Limbic leucotomy & 2 & 4 & I \\
\hline Kelly et $\mathrm{al}^{21}$ & Case series & 6 & Limbic leucotomy & 4 & 0 & 2 \\
\hline Göktepe et al ${ }^{25}$ & Case series & 4 & Subcaudate tractotomy & 0 & 2 & 2 \\
\hline $\begin{array}{l}\text { de Vaernet and } \\
\text { Madsen }{ }^{29}\end{array}$ & Case series & 6 & Amygdaloidotomy & 4 & 2 & 0 \\
\hline Kiloh et $\mathrm{al}^{27}$ & Case series & 4 & Amygdaloidotomy & 2 & 0 & 2 \\
\hline
\end{tabular}

Note: $n$, number of schizophrenic patients. 
nomena and the medial and orbital area of the frontal lobe modulate these responses". ${ }^{18}$

Three major limbic system circuits have been described, ie, the medial, basolateral, and defense reaction circuits. The medial limbic circuit is the classic Papez circuit, which has connections from the cingulate gyrus to the hippocampus, fornix, mammillary bodies, and anterior thalamic nucleus, and then to the orbitofrontal cortex and septal nuclei. The basolateral circuit involves the anterior temporal lobe, amygdala, mediodorsal thalamic nucleus, and orbitofrontal cortex. Note that the orbitofrontal cortex participates in both circuits. The defense reaction circuit does not seem to have any particular involvement in affective disorders. ${ }^{18}$

Many mechanisms involved in the effects of psychosurgery are not well established or are considered to result from limited understanding of brain functioning. The frontal leucotomy was proposed as a potential treatment for schizophrenia based on the fact that, by creating lesions in the prefrontal cortex, abnormal activity, presumably originating in this region, would be prevented from spreading to other areas of the brain, which could worsen the symptoms of the disease. ${ }^{19}$ The clinical utility of psychosurgery is currently based more on pragmatic analysis of reported efficacy than on knowledge of the scientific basis of the disease. ${ }^{20}$ For example, more than 1000 patients are known to have undergone cingulotomy for mental disorders. The percentage of patients who became "normal" with or without psychiatric care was approximately $18 \%$ of cases involving schizophrenia. ${ }^{20}$

\section{Surgical treatment}

At the beginning of the 1940s, encouraged by the first prefrontal lobotomies performed by Moniz and Lima, ${ }^{21}$ the American neurologist Walter Freeman and the neurosurgeon James Watts developed and popularized the closed lobotomy procedure in the US. This procedure consisted of bilateral insertion of leucotomes into $1 \mathrm{~cm}$ wide trepanations on each side of the frontal bone, where they were moved back and forth in order to section the white matter tracts in that cerebral region. ${ }^{22,23}$ Schizophrenia was one of the conditions for which this treatment was an option. ${ }^{21}$

Because this surgery caused extensive brain injuries leading to diverse complications, ${ }^{21}$ the classical lobotomy fell into disuse after the $1950 \mathrm{~s}$, being replaced by localized procedures isolating areas from the orbital and cingulate regions. These localized techniques culminated in stereotactic surgery that enabled the surgeon to insert a probe capable of injuring the brain tissue with tridimensional accuracy. The mortality rate and risk of epilepsy were reduced using this method. ${ }^{24}$ However, even after these advances, psychosurgery was progressively abandoned as a result of the advent of antipsychotic drugs during the 1950s, pressure of public opinion, ${ }^{24}$ and publication of studies on the adverse effects of the initial lobotomies performed. ${ }^{24}$

Nevertheless, psychosurgery survives, and the most important current techniques will be described here. During the last three decades, the most common procedures have included cingulotomy, subcaudate tractotomy, limbic leucotomy, anterior capsulotomy, and amygdaloidotomy ${ }^{23}$ (Figure 1).

\section{Anterior cingulotomy}

Cingulotomy is currently the most popular psychosurgical procedure performed in the US. ${ }^{23}$ Initially, it was performed as an open procedure, and results using stereotactic cingulotomy have recently been described..$^{23}$ The cingulate gyrus has been observed using air ventriculography, facilitating accurate ablation of the structure through bilateral trepanations and avoiding the need for craniotomy. ${ }^{21}$

This procedure is performed with stereotactic tools guided by magnetic resonance imaging. Two targets are identified on each side of the cingulate gyrus, $2-4 \mathrm{~cm}$ posterior to the anterior border of the frontal horn on the lateral ventricle, and approximately $7 \mathrm{~mm}$ lateral to the midline. Two trepanations are made approximately $9.5 \mathrm{~cm}$ posterior to the nasal bone and $1.5 \mathrm{~cm}$ lateral to the midline. The brain lesion is made by thermocoagulation using radiofrequency probes reaching $80^{\circ} \mathrm{C}-85^{\circ} \mathrm{C}$. Creation of the lesions takes approximately 60-100 seconds. The first lesion is created at a depth of $8 \mathrm{~mm}$ and the second is created $10 \mathrm{~mm}$ above the first, with the total lesion area being approximately $10 \times 20 \mathrm{~mm}$. Computed tomography is performed immediately after the surgical procedure to confirm the location of the lesion and check for hemorrhage. ${ }^{24}$

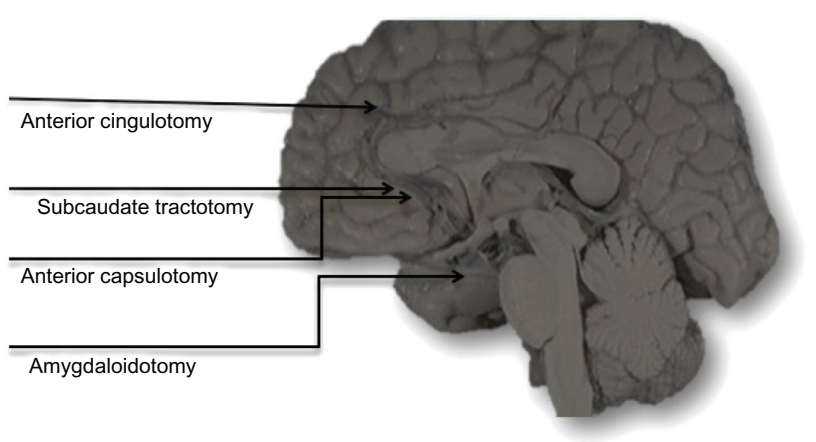

Figure I Possible target locations for patients with schizophrenia undergoing stereotactic surgery. 


\section{Subcaudate tractotomy}

Stereotactic subcaudate tractotomy was introduced in 1964. Radioactive yttrium (Y90) drops are implanted in the tissue to be damaged, ie, the substantia innominata, beneath the head of the caudate nucleus. ${ }^{24}$ Lesions are made in the subcaudate tractotomy by radiofrequency probes guided by magnetic resonance imaging. Three lesions, each approximately $8 \mathrm{~mm}$, are made bilaterally. All lesions are done in the coronal plane $15 \mathrm{~mm}$ above the base of the anterior clinoid process. The first lesion is located $6 \mathrm{~mm}$ lateral to the midline and $10 \mathrm{~mm}$ superior to the floor of the anterior fossa. The second is made $6 \mathrm{~mm}$ lateral to the midline and $15 \mathrm{~mm}$ superior to the floor of the anterior fossa. The third is located $14 \mathrm{~mm}$ lateral to the midline and $10 \mathrm{~mm}$ superior to the floor of the anterior fossa. ${ }^{24}$

\section{Limbic leucotomy}

Limbic leucotomy was introduced by Kelly and MitchellHeggs $^{21}$ in 1973 and is a combination of bilateral cingulotomy and subcaudate tractotomy. ${ }^{21}$ This group attempted to combine the benefits of both procedures to obtain relief of symptoms. ${ }^{25}$ The procedure is similar to the limbic leucotomy used in cingulotomy and subcaudate tractotomy, where the lesions are created in the respective targets using radiofrequency probes guided by magnetic resonance imaging.

\section{Anterior capsulotomy}

Anterior capsulotomy involves a lesion to the anterior limb of the internal capsule, containing radiating anterior thalamic fibers connecting the cortex to the pons..$^{23}$

In this procedure, magnetic resonance imaging is also used to identify the location of the structures. The targets are chosen in each hemisphere by $5 \mathrm{~mm}$ cuts in the coronal plane. The inferior target is $2-4 \mathrm{~mm}$ from the anterior horn of the lateral ventricle and the superior target is $1 \mathrm{~cm}$ above the inferior horn. Two bilateral trepanations are made immediately behind the coronal suture and the lesion is created by thermocoagulation through radiofrequency probes reaching $80^{\circ} \mathrm{C}-85^{\circ} \mathrm{C}$ for approximately 45 seconds. ${ }^{23}$ Radiosurgical lesioning (gamma capsulotomy) has also been used by Leksell's team. ${ }^{24}$ This lesioning technique involves the focus of 201 beams of ${ }^{60} \mathrm{Co}$ gamma radiation from a stereotactic gamma unit onto the lesion site. Although this procedure is not well understood, its efficacy seems to be similar to that of the radiofrequency thermolesioning procedure, with important advantages including elimination of the need for craniotomy and the safety of gamma radiation. ${ }^{24}$ This procedure is rarely performed.

\section{Amygdaloidotomy}

Using this procedure, the target is the amygdala. Clinical experience with stereotactic lesions of the amygdala has shown that amygdaloidotomy in a large percentage of cases resulted in a marked reduction in antisocial behavior. ${ }^{26,27}$ The amygdaloid target is determined using the data reported by Baird et al, ${ }^{28}$ with the intended center of the lesion being placed $5 \mathrm{~mm}$ medial to the medial border of the fissura. ${ }^{29}$

\section{Postoperative complications}

The classical lobotomy as performed by Freeman and Watts ${ }^{30}$ had a high rate of complications, and it was agreed by the end of the 1940s that it was not a desirable procedure, in that postoperatively, patients often became confused, frail, and languid, and some developed epilepsy. Long-term sequelae were known as the "frontal lobe syndrome", and included inertia, apathy, social withdrawal, and attention deficit. ${ }^{23,31}$ Bleeding is also another complication of this method, occasionally being fatal. ${ }^{23}$ Postoperative complications, including mortality, reduced considerably after the introduction of stereotactic surgery. ${ }^{24}$ Here we report the main complications that persist with the currently used stereotactic psychosurgery procedures.

Initial reports of cingulotomy indicated that despite having a significant risk of mortality, the results were more positive than those of open frontal leucotomies. ${ }^{25}$ In 1977 , Teuber et $\mathrm{al}^{32}$ reviewed the outcomes of cingulotomy for a wide range of patients, and noticed a small incidence of permanent cognitive deficits and surgical complications, with postoperative limitations in performing visuospatial tasks. Other complications of cingulotomy were identified, including transient mania and memory deficits. ${ }^{25}$ Cosgrove and Rauch noticed that, in more than 800 cingulotomies performed at their institution since 1962, there was no incidence of death or infection. Further, only two acute subdural hematomas, caused by laceration of the intracranial arteries during insertion of the probe, were observed. ${ }^{31}$ In 1987, a study by Ballantine et $\mathrm{al}^{33}$ showed that this procedure is relatively safe. There were no deaths as a result of surgery, and complications were limited to an epilepsy crisis in response to medication (1\%), hemiplegia $(0.3 \%)$, and suicide $(9 \%)$. Of note, these suicides occurred in patients who had already had suicidal thoughts before surgery.

Probably the most comprehensive review on subcaudate tractotomy was that published by Göktepe et al in 1975. ${ }^{25}$ These authors reported a few complications, including epileptic crisis in the postoperative period (2.2\%) and adverse personality changes $(6.7 \%)$. Transient symptoms, including 
confusion and memory deficits, are attributed to postoperative edema. One death was reported as a result of migration of a $90 \mathrm{Y}$ drop to the hypothalamus. ${ }^{32}$ Many of these complications were mitigated after replacing 90Y drops with radiofrequency ablation. ${ }^{25}$

Long-term collateral effects after limbic leucotomy are rare, but transient effects including headache, confusion, lethargy, and sphincter disturbances have been reported. These symptoms can take several months to disappear. ${ }^{25}$

Rare complications have been reported following anterior capsulotomy, including intracranial hemorrhage, enuresis, epileptic crisis, fatigue, loss of initiative, aggressiveness, memory deficit, and weight gain. ${ }^{21,25}$

\section{Prognosis}

The results of our analysis indicate significant symptomatic improvement in $57 \%$ of cases. However, although improvement is seen in affective symptoms, no studies have demonstrated improvement in psychotic symptoms (Table 1).

Some investigators have been able to analyze the prognosis of schizophrenia in patients undergoing different types of psychosurgery. For example, Freeman ${ }^{34}$ found that lobotomy, when performed before the development of severe schizophrenia, reduced the likelihood of progression of the disease. On the other hand, Dynes ${ }^{35}$ found that some patients, even after undergoing classical lobotomy, remained hospitalized for more than a decade and it "seemed like the surgery had hastened the intellectual deterioration observed in many chronic schizophrenic patients". Because violent behavior and agitation improved initially, Miller urged that psychosurgery should be considered for problematic and intractable psychological disorders. ${ }^{36}$ The findings of a study reported by Freeman in 1973 showed that the increasing number of therapeutic solutions available to psychiatrists resulted in a reduction in the use of psychosurgery for nonorganic psychiatric disorders, but Freeman considered that patients who did not respond to medical treatment should still be evaluated as possible candidates for psychosurgery. ${ }^{34}$

Some reviews have reported on the role of lobotomy in the treatment of schizophrenia. Tooth and Newton ${ }^{37}$ investigated more than 7500 patients with schizophrenia who had undergone frontal lobotomy in England from 1942 to 1952. Only $18 \%$ of these patients showed signs of improvement. However, another study of frontal lobotomy reported that the original and bimedial lobotomies had some therapeutic benefits in patients with schizophrenia unresponsive to conventional therapeutic measures. ${ }^{24}$ Moreover, in a study of patients with severe and chronic schizophrenia who had undergone lobotomy 40 years earlier, it was noted that there was no improvement or relief of symptoms after the patients became elderly. ${ }^{24}$ However, as stated by the author, there is no clear evidence for psychosurgery contraindication in particular cases of schizophrenia.

The results seem to be better for stereotactic psychosurgery. In a report by Da Costa, ${ }^{24} 16$ patients were classified as severe, chronic, or untreatable. After undergoing bilateral stereotactic lobotomy, $31 \%$ of these patients did not exhibit any aggressive behavior, 56\% improved markedly, and $13 \%$ showed slight improvement. The psychiatric evolution according to the tests was:

- Brief Psychiatric Rating Scale - mean score decreased from $56 \pm 11.3$ preoperatively to $32.7 \pm 7.5$ postoperatively $(P<0.05)$

- Rorschach test - increased cognitive and affective control in 11 of 16 patients

- Wechsler Adult Intelligence Scale - no significant statistical difference seen between preoperative and postoperative results

- Luria Nebraska Neuropsychological Battery - significant improvement in rhythm, intellectual, and visual processing, as well as memory, in all patients.

These findings show that introduction of new stereotactic techniques markedly improved the prognosis of patients. ${ }^{24} \mathrm{As}$ with other types of psychosurgery, unsatisfactory outcomes were observed in patients with schizophrenia who underwent anterior capsulotomy. ${ }^{25}$

Improvement was noted in $80 \%$ of patients who underwent limbic lobotomy for schizophrenia. However, much of this improvement involved the strong affective component of the disease. Interestingly, the number of psychotic events was also reduced in these patients. ${ }^{25}$

In 1987, Ballantine et al ${ }^{33}$ reported a 24-year study involving 198 patients who underwent anterior cingulotomy with a follow-up period of 8.6 years. The results showed that four of 11 patients experienced considerable improvement, according to a $0-5$ categorical rating scale to categorize the patient's current, global, and psychosocial status. This study showed that these patients had no deficit in intellectual or emotional function. In fact, the experiment reported no change in the degree of intellectual or emotional behavior (aside from a decrease in the Taylor Complex Figure Task in patients over 40 years of age) and indicated a postoperative gain in intelligence quotient on the Wechsler test. ${ }^{34}$ Bridges et al indicated that, similar to cingulotomy, stereotactic subcaudate tractotomy had little impact on psychoses, including schizophrenia. ${ }^{38}$ 
Talairach and Tournoux, who pioneered selective surgical lesioning of the internal capsule as a treatment for psychiatric disorders, observed that the outcomes of anterior capsulotomy were not satisfactory in psychotic patients. ${ }^{39}$ Moreover, according to Herner, ${ }^{40}$ the initial outcomes of capsulotomy for the treatment of schizophrenia were disappointing, with only $27 \%$ of patients having a positive response.

Our search identified two studies of amygdaloidotomy published in the 1970s. The operation was performed in schizophrenic patients with aggressive behavior and/or a marked tendency towards self-mutilation. Eighty percent of the patients showed improvement in aggressiveness, but hallucinations tended to persist. $^{21,25}$

\section{Recent developments}

Transcranial magnetic stimulation is a relatively recent and promising method for both investigation and treatment of psychiatric and neurologic disorders. ${ }^{41-43}$ Transcranial magnetic stimulation experiments have been performed in schizophrenic patients with encouraging results. Hoffman et al used this technique in patients with schizophrenia or schizoaffective disorder, ${ }^{44}$ all of whom had medication-resistant auditory hallucinations. It was observed that $52 \%$ of the patients had sustained improvement in their symptoms for at least 15 weeks, and the largest effect was on the frequency of hallucinations. Prikryl et al reported recently that repetitive transcranial magnetic stimulation has a positive effect on working memory and neuronal activation in the treatment of the negative symptoms of schizophrenia. ${ }^{45}$ Poulet et al, in a systematic review of the literature report that, overall, repetitive transcranial magnetic stimulation studies have demonstrated some promise in the treatment of schizophrenia. ${ }^{46}$ Results such as these, combined with recent pathophysiological studies, generate a scientific basis on which to base the development of brain stimulation techniques with electrodes that are similar to those used for the treatment of Parkinson's disease ${ }^{47}$ This technique has the advantage of being minimally invasive, as well as being reversible.

\section{Conclusion}

Despite the development of atypical antipsychotics such as clozapine, recent epidemiological studies show that a large percentage of patients still have serious limitations as a result of schizophrenia. Furthermore, the impact of the disease on quality of life and the potential damage that patients can do to themselves and others have encouraged the exploration of less conservative therapies, such as psychosurgery. However, use of such procedures remains controversial. There is still no evidence base to support the use of stereotactic procedures for schizophrenia. Well designed controlled studies are still needed to establish the effectiveness of psychosurgery in patients with the disease. There remain legal and ethical issues concerning psychosurgery, and outcomes have been unfavorable in the past. However, the development of minimally invasive and even reversible techniques, combined with solid anatomical and physiological concepts, should enable psychosurgery to be considered as an alternative treatment for schizophrenia in the future.

\section{Disclosure}

The authors report no conflicts of interest in this work.

\section{References}

1. Gross CG. 'Psychosurgery' in Renaissance art. Trends Neurosci. 1999;22:429-431.

2. Stone JL. Dr Gottlieb Burckhardt - the pioneer of psychosurgery. J Hist Neurosci. 2001;10:79-92.

3. Mallett R, Leff J, Bhugra D, Pang D, Zhao JH. Social environment, ethnicity and schizophrenia. A case-control study. Soc Psychiatry Psychiatr Epidemiol. 2002;37:329-335.

4. Ustun TB. The global burden of mental disorders. Am J Public Health. 1999;89:1315-1318.

5. Andreasen NC. Schizophrenia: the fundamental questions. Brain Res Brain Res Rev. 2000;31:106-112.

6. Maguire GA. Comprehensive understanding of schizophrenia and its treatment. Am J Health Syst Pharm. 2002;59(17 Suppl 5):S4-S11.

7. Thomas HV, Dalman C, David AS, Gentz J, Lewis G, Allebeck P. Obstetric complications and risk of schizophrenia. Effect of gender, age at diagnosis and maternal history of psychosis. Br J Psychiatry. 2001;179:409-414.

8. Jablensky A. Epidemiology of schizophrenia: the global burden of disease and disability. Eur Arch Psychiatry Clin Neurosci. 2000;250: 274-285.

9. Thara R, Eaton WW. Outcome of schizophrenia: the Madras longitudinal study. Aust N Z J Psychiatry. 1996;30:516-522.

10. van Os J, McGuffin P. Can the social environment cause schizophrenia? Br J Psychiatry. 2003;182:291-292.

11. [No authors listed]. Health care reform for Americans with severe mental illnesses: Report of the National Advisory Mental Health Council. Am J Psychiatry. 1993;150:1447-1465.

12. Neugebauer R. Mind matters: the importance of mental disorders in public health's 21st century mission. Am J Public Health. 1999;89: 1309-1311.

13. Walsh E, Buchanan A, Fahy T. Violence and schizophrenia: examining the evidence. Br J Psychiatry. 2002;180:490-495.

14. Radomsky ED, Haas GL, Mann JJ, Sweeney JA. Suicidal behavior in patients with schizophrenia and other psychotic disorders. $\mathrm{Am} \mathrm{J}$ Psychiatry. 1999;156:1590-1595.

15. Caldwell CB, Gottesman II. Schizophrenics kill themselves too: a review of risk factors for suicide. Schizophr Bull. 1990;16:571-589.

16. Moldin SO, Gottesman II. At issue: genes experience and chances in schizophrenia-positioning for the 21st century. Schizophr Bull. 1997;23:547-561.

17. Jenkins RL, Holsopple JQ, Lorr M. Effects of prefrontal lobotomy on patients with severe chronic schizophrenia. Am J Psychiatry. 1954;111:84-90.

18. Goumeniouk AD, Clark CM. Prefrontal lobotomy and hypofrontality in patients with schizophrenia: an integration of the findings. Can $J$ Psychiatry. 1992;37:17-22. 
19. Carnahan H, Elliott D, Velamoor VR. Manual performance in leukotomized and unleukotomized individuals with schizophrenia. Schizophr Res. 1995;17:267-278.

20. Hall P. Consent for surgery for psychiatric patients. BMJ. 1993;306: 930.

21. Kelly D, Mitchell-Heggs N. Stereotactic limbic leucotomy - a follow-up study of thirty patients. Postgrad Med J. 1973;49:865-882.

22. Mitchell-Heggs N, Kelly D, RichardsonA. Stereotactic limbic leucotomya follow-up at 16 months. Br J Psychiatry. 1976;128:226-240.

23. Jiménez-Ponce F, Soto-Abraham JE, Ramírez-Tapia Y, VelascoCampos F, Carrillo-Ruiz JD, Gómez-Zenteno P. [Evaluation of bilateral cingulotomy and anterior capsulotomy for the treatment of aggressive behavior.] Cir Cir. 2011;79:107-113. [Spanish].

24. da Costa DA. The role of psychosurgery in the treatment of selected cases of refractory schizophrenia: a reappraisal. Schizophr Res. 1997;28: 223-230.

25. Göktepe EO, Young LB, Bridges PK. A further review of the results of sterotactic subcaudate tractotomy. Br J Psychiatry. 1975;126: 270-280.

26. Narabayashi H, Nagao T, Saito T, Yoshida M, Nagahata M. Stereotaxic amygdalotomy for behaviour disorders. Arch Neurol. 1963;9:1-16.

27. Kiloh LG, Gye RS, Rushworth RG, Bell DS, White RT. Stereotactic amygdaloidotomy for aggressive behaviour. J Neurol Neurosurg Psychiatry. 1974;37:437-444.

28. Baird HW 3rd, Spiegel EA, Wycis HT. Studies in stereoencephalotomy. IX. The variability in the extent and position of the amygdala. Confin Neurol. 1960;20:26-36.

29. de Vaernet K, Madsen A. Stereotaxic amygdalotomy and basofrontal tractotomy in psychotics with aggressive behaviour. J Neurol Neurosurg Psychiatry. 1970;33:858-863.

30. Freeman W, Watts JW. Psychosurgery: An Evaluation of Two Hundred Cases over Seven Years. Journal of Mental Science. 1944;90(379):532-537.

31. Cosgrove GR, Rauch SL. Psychosurgery. Neurosurg Clin N Am. 1995;6:167-176.

32. Teuber JL, Corkin SH, Twitchell TE. Study of cingulotomy in man: a summary. In: Sweet WH, Obrator S, Martin-Rodriguez JG, editors. Neurosurgical Treatment in Psychiatry, Pain, and Epilepsy. Baltimore, MD: University Park Press; 1977.

33. Ballantine HT Jr, Bouckoms AJ, Thomas EK, Giriunas IE. Treatment of psychiatric illness by stereotactic cingulotomy. Biol Psychiatry. 1987;22:807-819.
34. Freeman W. Frontal lobotomy in early schizophrenia. Long follow-up in 415 cases. Br J Psychiatry. 1971;119:621-624.

35. Dynes JB. Lobotomy - 20 years later. VA Med Mon. 1968;95:306-308.

36. Miller BL, Cummings JL. The Human Frontal Lobes: Functions and Disorders. Guilford Press; 2007. p. 505-517.

37. Tooth GC, Newton MP. Leucotomy in England and Wales 1942-1954. Reports on Public Health and Medical Subjects, No 104. Ministry of Health, London, UK: Her Majesty's Stationery Office; 1961.

38. Bridges PK, Bartlett JR, Hale AS, Poynton AM, Malizia AL, Hodgkiss AD. Psychosurgery: stereotactic subcaudate tractotomy. An indispensable treatment. Br J Psychiatry. 1994;165:599-611.

39. Talairach J, Tournoux P. Co-Planar Stereotaxic Atlas of the Human Brain: 3-Dimensional Proportional System - An Approach to Cerebral Imaging. New York, NY: Thieme Medical Publishers; 1988.

40. Herner T. Treatment of mental disorders with frontal stereotactic thermo lesions: A follow-up of 116 cases. Acta Psychiatr Scand. 1961; Suppl 158:36.

41. Rossini PM, Rossi S. Transcranial magnetic stimulation: diagnostic, therapeutic, and research potential. Neurology. 2007;68:484-488.

42. Minichino A, Bersani FS, Capra E, et al. ECT, rTMS, and deepTMS in pharmacoresistant drug-free patients with unipolar depression: a comparative review. Neuropsychiatr Dis Treat. 2012;8:55-64.

43. Paiva WS, Fonoff ET, Marcolin MA, Cabrera HN, Teixeira MJ. Cortical mapping with navigated transcranial magnetic stimulation in low-grade glioma surgery. Neuropsychiatr Dis Treat. 2012;8:197-201.

44. Hoffman RE, Hawkins KA, Gueorguieva R, et al. Transcranial magnetic stimulation of left temporoparietal cortex and medication-resistant auditory hallucinations. Arch Gen Psychiatry. 2003;60:49-56.

45. Prikryl R, Mikl M, Prikrylova Kucerová H, et al. Does repetitive transcranial magnetic stimulation have a positive effect on working memory and neuronal activation in treatment of negative symptoms of schizophrenia? Neuro Endocrinol Lett. 2012;33:90-97.

46. Poulet E, Haesebaert F, Saoud M, Suaud-Chagny MF, Brunelin J. Treatment of schizophrenic patients and rTMS. Psychiatr Danub. 2010; 22 Suppl 1:S143-S146.

47. Larson PS. Neurotherapeutics. Deep brain stimulation for psychiatric disorders. Neurotherapeutics. 2008;5:50-58.
Neuropsychiatric Disease and Treatment

\section{Publish your work in this journal}

Neuropsychiatric Disease and Treatment is an international, peerreviewed journal of clinical therapeutics and pharmacology focusing on concise rapid reporting of clinical or pre-clinical studies on a range of neuropsychiatric and neurological disorders. This journa is indexed on PubMed Central, the 'PsycINFO' database and CAS.

\section{Dovepress}

The manuscript management system is completely online and includes a very quick and fair peer-review system, which is all easy to use. Visit http://www.dovepress.com/testimonials.php to read real quotes from published authors. 